\title{
Graphene-Based Antibacterial Paper
}

\author{
Wenbing Hu, Cheng Peng, Weijie Luo, Min Lv, Xiaoming Li, Di Li, Qing Huang,* and Chunhai Fan* \\ Laboratory of Physical Biology, Shanghai Institute of Applied Physics, Chinese Academy of Sciences, \\ Shanghai 201800, People's Republic of China
}

G raphene is a monolayer of carbon atoms that are tightly packed into a two-dimensional crystal. ${ }^{1}$ This extremely thin nanomaterial possesses very high mechanical stiffness ${ }^{2-4}$ and extraordinary electronic transport properties. ${ }^{5-10}$ Since the seminal work of Geim and coworkers on freestanding graphene in 2004, ${ }^{5}$ various forms of graphene sheets have been actively explored ${ }^{11}$ with novel applications such as transistors, ${ }^{12-14}$ solar cells, ${ }^{15-17}$ and sensors. ${ }^{18,19}$ While biological studies of graphene are relatively limited, significant recent attention has been drawn toward interactions between graphene derivatives and bioorganisms. ${ }^{20-22}$ Here, we interrogate interactions between graphene oxide (GO) nanosheets and bacterial and mammalian cells and report our novel finding on the excellent antibacterial activity and minimal cytotoxicity of GO nanosheets. Particularly, we demonstrate that macroscopic antibacterial graphene-based paper can be conveniently fabricated with superior inhibition ability to bacteria growth, suggesting the promising environmentally friendly applications of these low-cost and highly effective carbon nanomaterials.

Antibacterial materials are widely used in daily life and effectively protect the public health. A wide range of materials, including antibiotics, ${ }^{23}$ metal ions, ${ }^{24}$ and quaternary ammonium compounds, ${ }^{25}$ have been known to prevent attachment and proliferation of microbes on material surfaces. However, these materials are known to be associated with concerns about antibiotic resistance, environmental pollution, relatively complex processing, and high cost. ${ }^{26,27}$ More recently, antibacterial properties of nanomaterials have been explored to meet these challenges, including silver
ABSTRACT Graphene is a monolayer of tightly packed carbon atoms that possesses many interesting properties and has numerous exciting applications. In this work, we report the antibacterial activity of two waterdispersible graphene derivatives, graphene oxide (G0) and reduced graphene oxide ( $\mathrm{rG0}$ ) nanosheets. Such graphene-based nanomaterials can effectively inhibit the growth of $E$. coli bacteria while showing minimal cytotoxicity. We have also demonstrated that macroscopic freestanding $\mathrm{GO}$ and $\mathrm{rGO}$ paper can be conveniently fabricated from their suspension via simple vacuum filtration. Given the superior antibacterial effect of $\mathrm{GO}$ and the fact that $\mathrm{GO}$ can be mass-produced and easily processed to make freestanding and flexible paper with low cost, we expect this new carbon nanomaterial may find important environmental and clinical applications.

KEYWORDS: graphene oxide - reduced graphene oxide - minimal cytotoxicity · antibacterial activity $\cdot$ graphene oxide paper

nanoparticles, ${ }^{28}$ titanium oxide nanoparticles, ${ }^{29}$ and carbon nanotubes (CNTs). CNTs are another type of carbon nanomaterials and can be regarded as rolled graphene. ${ }^{1}$ CNTs have been found to be cytotoxic, ${ }^{30-32}$ unless via elaborate surface functionalization, ${ }^{33}$ to both human cells and bacteria. Very recently, graphene paper has been found to be a biocompatible substrate for adhesion and proliferation of L-929 cells, ${ }^{20}$ neuroendocrine PC12 cells, oligodendroglia cells, and osteoblasts, ${ }^{34}$ and graphene oxide has been employed as an effective nanocargo to deliver water-insoluble drugs into cells. ${ }^{21,22}$ This has motivated us to explore the cytotoxicity of graphene and its antiseptic properties.

\section{RESULTS AND DISCUSSION}

\section{Preparation and Characterization of $\mathbf{G O}$}

Nanosheets and Paper. GO nanosheets are a chemically modified graphene with suspended hydroxyl, epoxyl, and carboxyl functional groups, ${ }^{8}$ which enable them to be readily dispersed in water. GO nanosheets were prepared according to a modified Hummer method, resulting in a brown colloidal suspension. ${ }^{35}$ The thickness $\odot 2010$ American Chemical Society 

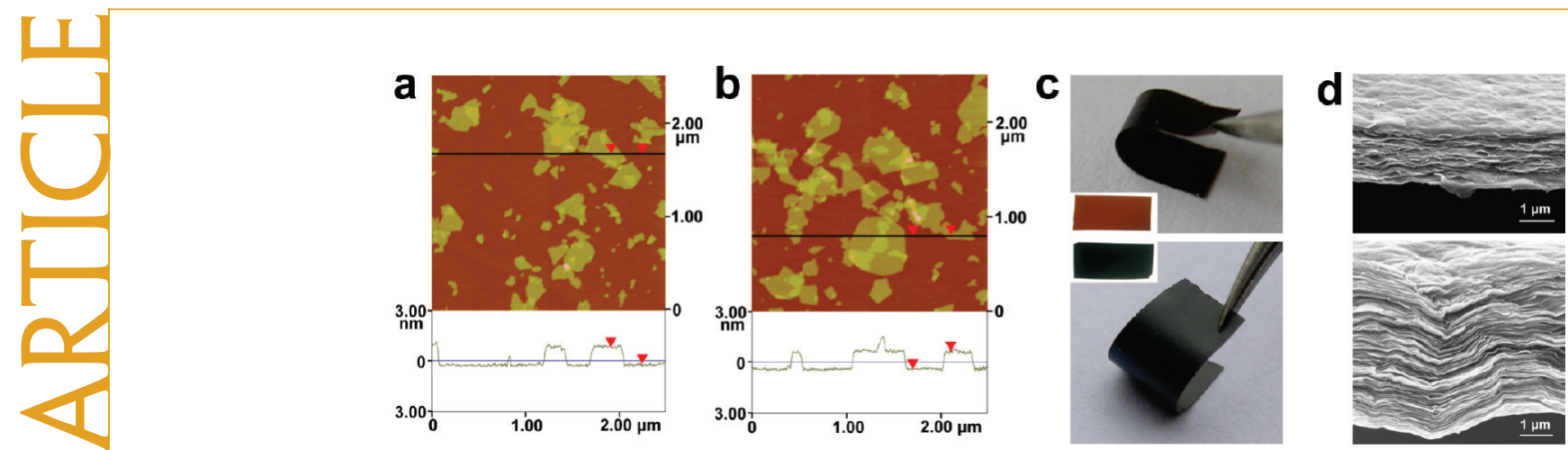

Figure 1. Characterization of GO and rGO nanosheets and paper. AFM images of (a) GO and (b) rGO sheets. (c) Photographs of freestanding and flexible GO (top) and rGO paper (bottom) (inset of (c), the photos of GO (top) and rGO (bottom) paper penetrated by white light). (d) Thickness of GO (top) and rGO (bottom) paper as measured via SEM.

of the GO sheets was $\sim 1.1 \mathrm{~nm}$ as measured via atomic force microscopy (AFM), suggesting the formation of a single-layer 2-D nanomaterial (Figure 1a). Hydrazine reduction of GO led to a black rGO suspension, a more conductive version of $\mathrm{GO}$ nanosheets with less surface defects. AFM measurements revealed that $\mathrm{KGO}$ had a reduced sheet thickness of $\sim 1.0 \mathrm{~nm}$ (Figure $1 \mathrm{~b}$ ), which was possibly attributed to partial removal of oxygen functional groups on the surface of GO nanosheets during the reduction process. GO and rGO nanosheets were fairly polydispersed with lateral dimensions ranging from nanometers to micrometers.

Both GO and rGO nanosheets could be easily made into macroscopic, freestanding, robust, and flexible paper via a one-step vacuum filtration protocol. ${ }^{36,37}$

Such graphene materials in the paper form are easy to use and have potential practical applications. The GO paper had a thickness of $\sim 1.5 \mu \mathrm{m}$ and that of the rGO paper was $\sim 4.6 \mu \mathrm{m}$, as characterized by scanning electron microscopy (SEM). Interestingly, the GO paper looked lackluster while the rGO paper was lustrous (Figure $1 c, d$ ), which was possibly due to the marked difference in electronic properties of GO and $\mathrm{rGO}$ nanosheets.

Cellular Uptake and Cytotoxicity of GO Nanosheets. We first evaluated the cellular uptake and cytotoxicity of GO nanosheets $(85 \mu \mathrm{g} / \mathrm{mL})$ with a mammalian cell line, A549. Transmission electron microscopy (TEM) studies a

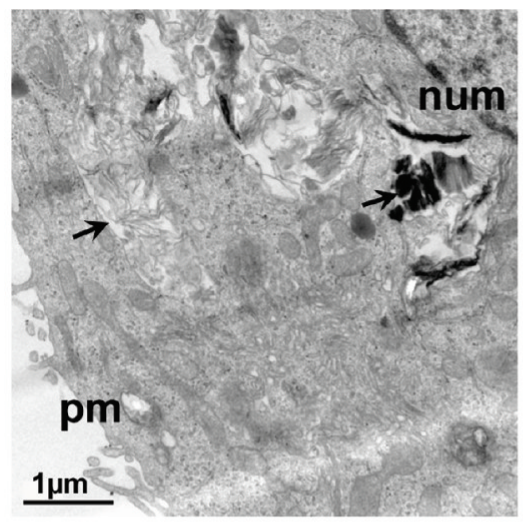

b

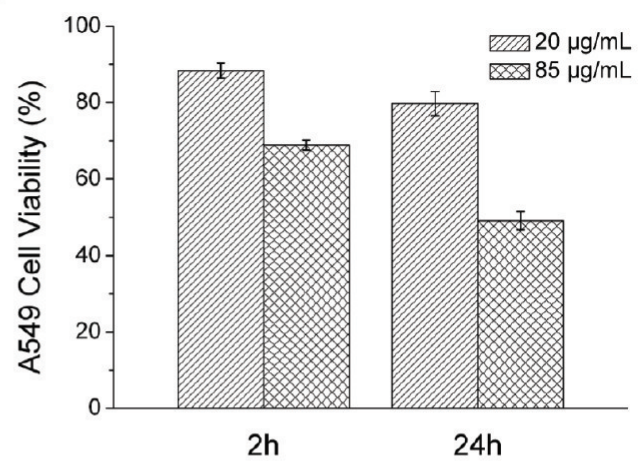

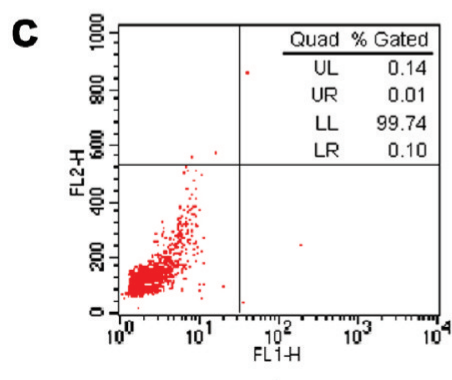

$0 \mu \mathrm{g} / \mathrm{mL}$
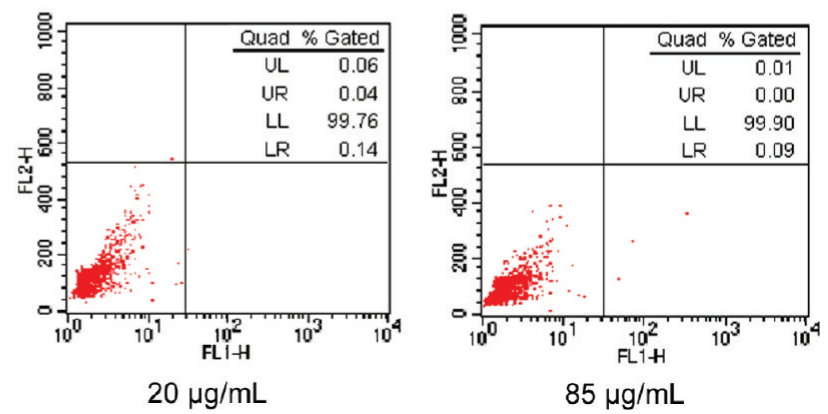

Figure 2. Cellular uptake and cytotoxicity of GO nanosheets. (a) TEM images of A549 cells incubated with $85 \mu \mathrm{g} / \mathrm{mL} \mathrm{GO}$ nanosheets for $6 \mathrm{~h}$. GO nanosheets were internalized in A549 cells (indicated by arrows). "pm" and "num" stand for plasma membrane and nuclear membrane. The light-colored parts marked with an arrow were ascribed to single- or few-layer GO sheets, while the black parts were GO aggregates. (b) Viability of cells incubated with 20 and $85 \mu \mathrm{g} / \mathrm{mL} \mathrm{GO}$ nanosheets for $2 \mathrm{~h}$ and $24 \mathrm{~h}$. (c) Distribution of A549 cells without GO nanosheet treatment (left) and treated with $20 \mu \mathrm{g} / \mathrm{mL}$ (middle) and 85 $\mu \mathrm{g} / \mathrm{mL}$ (right) GO for $24 \mathrm{~h}$. 


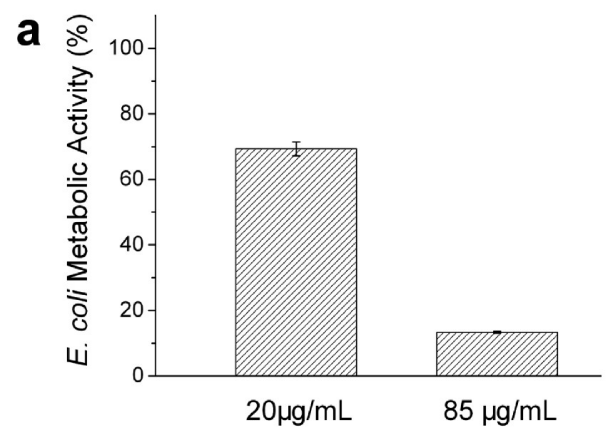

b
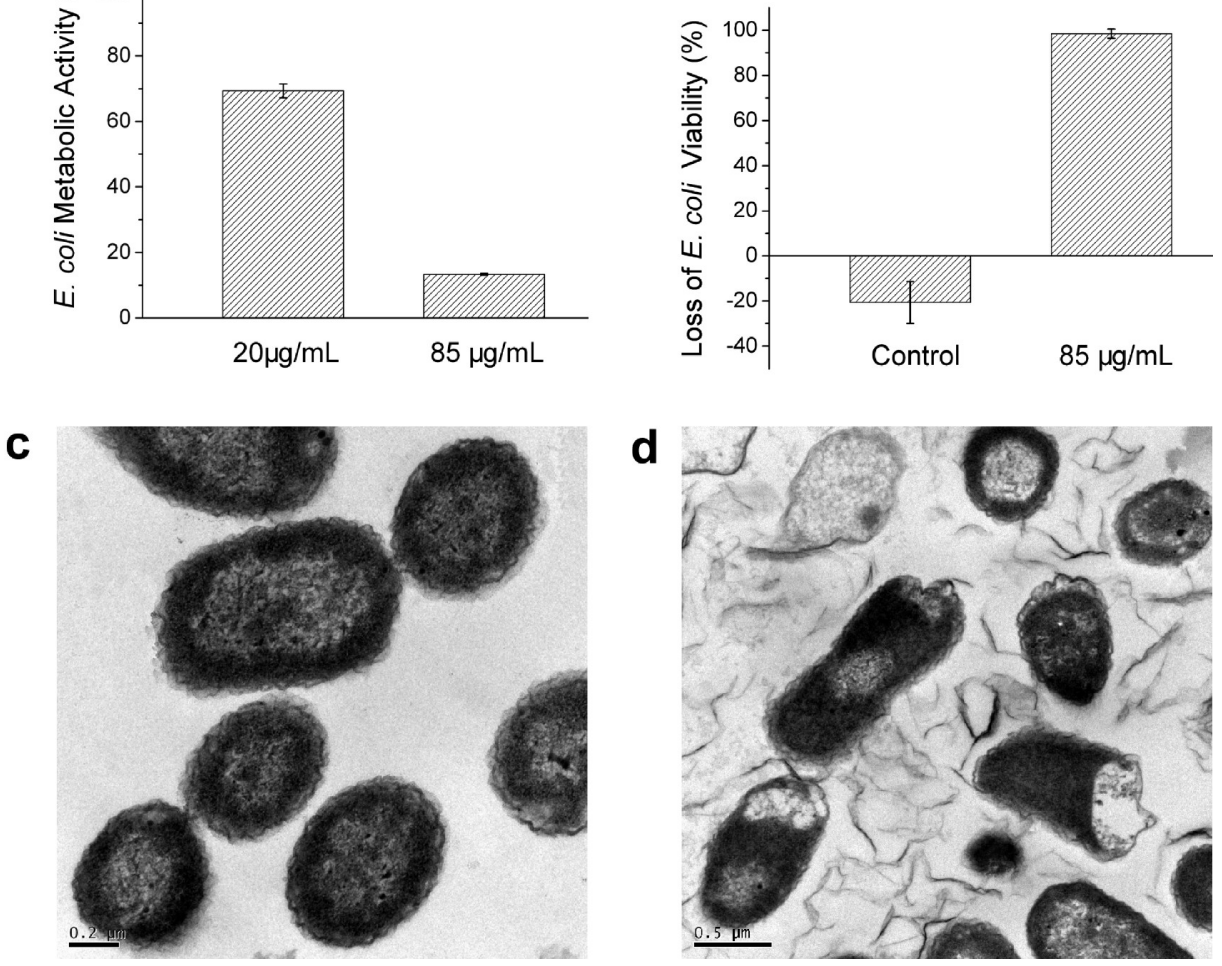

Figure 3. Antibacterial activity of GO nanosheets. (a) Metabolic activity of $E$. coli incubation with 20 and $85 \mu \mathrm{g} / \mathrm{mL} \mathrm{GO}$ nanosheets at $37^{\circ} \mathrm{C}$ for $2 \mathrm{~h}$. (b) Antibacterial activity of $85 \mu \mathrm{g} / \mathrm{mL}$ GO nanosheets against E. coli DH5 $\alpha$ cells. TEM images of E. coli (c) and E. coli exposed to $\mathrm{GO}$ nanosheets at $37^{\circ} \mathrm{C}$ for $2 \mathrm{~h}$ (d).

demonstrated that $\mathrm{GO}$ nanosheets were inside the endosome of the cytoplasm (Figure 2a and Figure S2 (Supporting Information)), suggesting that $\mathrm{GO}$ nanosheets could be internalized within A549 cells via endocytosis. ${ }^{21}$ The metabolic activity assays based on succinate dehydrogenase activity in the mitochondria showed that $\mathrm{GO}$ nanosheets $(20 \mu \mathrm{g} / \mathrm{mL})$ exhibited no cytotoxicity to $\mathrm{A} 549$ within $2 \mathrm{~h}$ incubation and a slight decrease in cell viability $(\sim 20 \%)$ within $24 \mathrm{~h}$. GO nanosheets of higher concentration $(85 \mu \mathrm{g} / \mathrm{mL})$ led to an increased cytotoxicity ( $\sim 50 \%)$ within $24 \mathrm{~h}$ (Figure $2 \mathrm{~b}$ ).

Flow cytometric analysis provided a mechanistic study of the interaction of GO nanosheets with A549 cells. Interestingly, we found that apoptosis did not occur in A549 cells treated with GO nanosheets of both 20 and $85 \mu \mathrm{g} / \mathrm{mL}$ for $24 \mathrm{~h}$ (Figure 2c). Cell cycle analysis showed that the percentage of cells in the $G_{0} / G_{1}$ phase slightly increased (Table S1 (Supporting Information)) and those in the $G_{2} / M$ phase almost multiplied, while those in the $S$ phase significantly decreased, which suggested that GO-treated A549 cells were kept in the $G_{2}$ phase (mitosis metaphase) rather than passing the check point to replicate DNA. We further counted the numbers of A549 cells treated with GO nanosheets for $24 \mathrm{~h}$. Interestingly, the number of untreated cells was 3.11-fold that of seeded cells (Table S1), while the number of cells treated with GO nanosheets of $85 \mu \mathrm{g} / \mathrm{mL}$ proliferated 2.78-fold. Overall, these data strongly im- plied that the observed small decrease in cell viability might arise from GO-retarded cell cycles and thus slightly decreased proliferation rates, rather than from apoptosis or death of cells. Therefore, we concluded that $\mathrm{GO}$ nanosheets were relatively biocompatible nanomaterials with mild cytotoxicity.

Antibacterial Activity of $\mathbf{G O}$ Nanosheets. We then evaluated the antibacterial activity of GO nanosheets by investigating the interaction the $E$. coli $\mathrm{DH} 5 \alpha$ cells with $\mathrm{GO}$ nanosheets. The metabolic activity of $E$. coli $\mathrm{DH} 5 \alpha$ cells in the presence of $\mathrm{GO}$ nanosheets was measured via a luciferase-based ATP assay kit. After $2 \mathrm{~h}$ incubation with $\mathrm{GO}$ nanosheets of $20 \mu \mathrm{g} / \mathrm{mL}$ at $37^{\circ} \mathrm{C}$, the cell metabolic activity for $E$. coli deceased to $\sim 70 \%$ and to $\sim 13 \%$ at a GO nanosheet concentration of $85 \mu \mathrm{g} / \mathrm{mL}$ (Figure $3 a)$, suggesting the strong inhibition ability of $\mathrm{GO}$ nanosheets to $E$. coli. We also employed a classic colony counting method to measure the microbial viability of E. coli treated with $85 \mu \mathrm{g} / \mathrm{mL} \mathrm{GO}$ for 2 h. Significantly, we found that $\mathrm{GO}$ almost completely suppressed the growth of $E$. coli, leading to a viability loss up to $98.5 \%$ (Figure 3b). A control study was performed with GOfree supernatant that removed $G O$ nanosheets via centrifugation, which did not induce the apparent bacterial suppression effect with overnight incubation at $37^{\circ} \mathrm{C}$ (Figure S3 (Supporting Information)). These results further confirmed that $\mathrm{GO}$ nanosheets were responsible for the observed strong antibacterial effect. TEM 


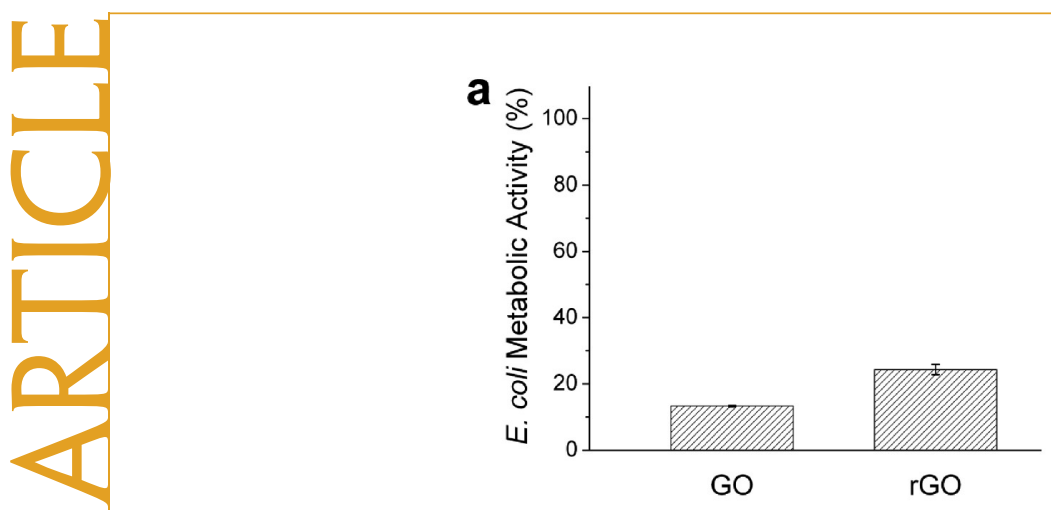

b
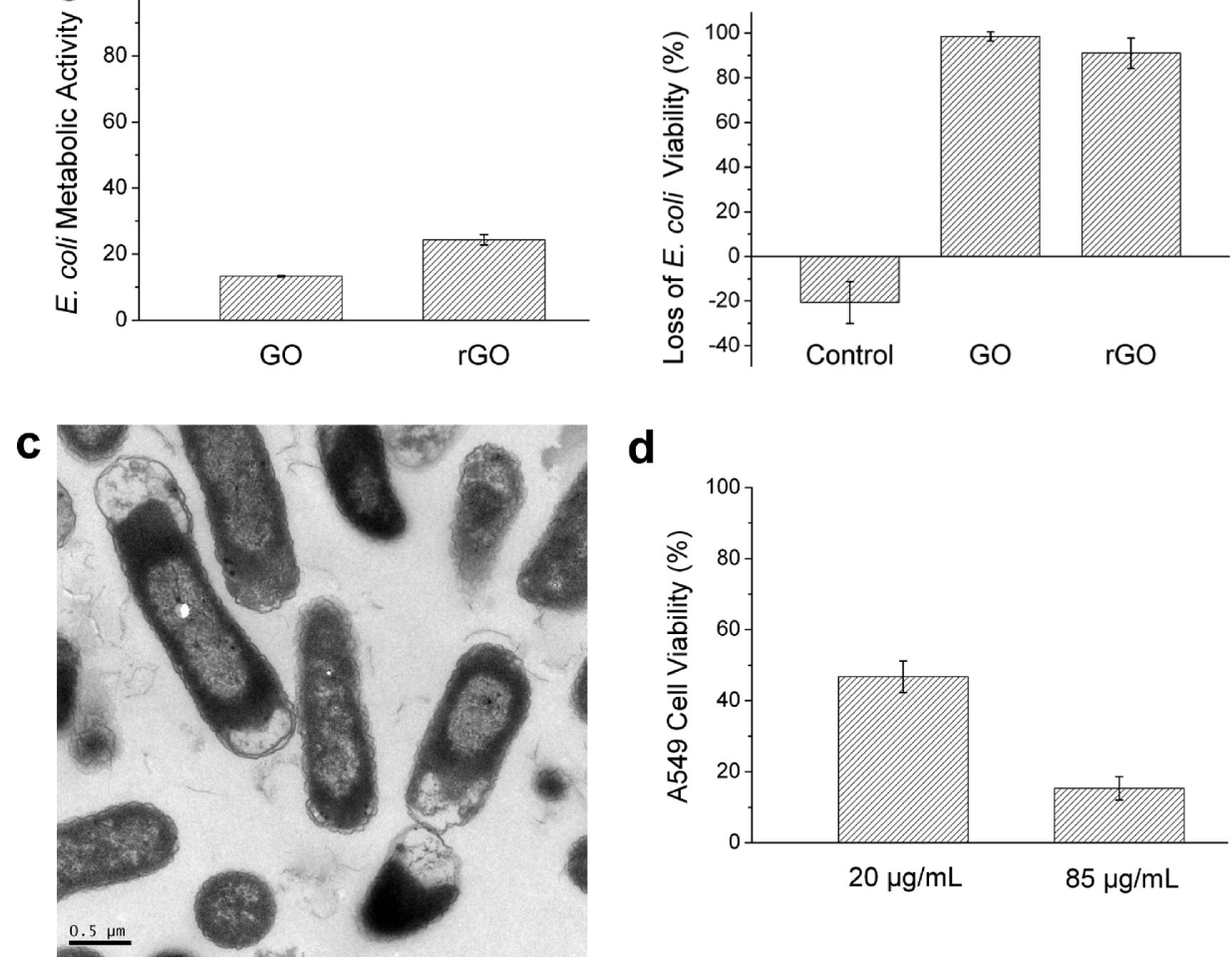

\section{d}

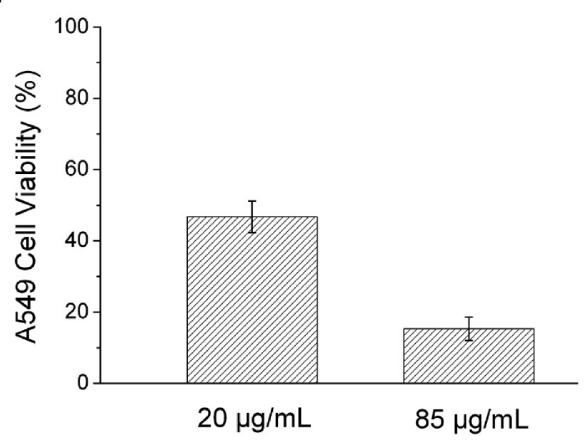

Figure 4. Antibacterial activity and cytotoxicity of rGO nanosheets. (a) Metabolic activity of $E$. coli treated with $85 \mu \mathrm{g} / \mathrm{mL}$ $\mathrm{GO}$ and $\mathrm{rGO}$ nanosheets, respectively. (b) Antibacterial activity of $85 \mu \mathrm{g} / \mathrm{mL} \mathrm{GO}$ and $\mathrm{rGO}$ nanosheets against $E$. coli. (c) TEM image of $E$. coli exposed to $85 \mu \mathrm{g} / \mathrm{mL} \mathrm{rGO}$ nanosheets at $37^{\circ} \mathrm{C}$ for $2 \mathrm{~h}$. (d) Viability of A549 cell incubated with 20 and 85 $\mu \mathrm{g} / \mathrm{mL}$ rGO nanosheets, respectively.

studies revealed that E. coli largely lost cellular integrity, with the cell membrane being severely destroyed and the cytoplasm flowing out (Figure 3c,d). Such irreversible GOinduced cellular damage of $E$. coli might arise from the effects of either oxidative stress or physical disruption that have been observed in cellular effects of related carbon nanomaterial (CNTs and fullerene). ${ }^{38-44}$

Antibacterial Activity and Cytotoxicity of $\mathrm{rGO}$ Nanosheets.

The reduced form of GO nanosheets, rGO nanosheets, also exhibited high antibacterial effects. The metabolic activity of $E$. coli $\mathrm{DH} 5 \alpha$ cells was reduced to $\sim 24 \%$ on treatment with rGO nanosheets of $85 \mu \mathrm{g} / \mathrm{mL}$ at $37^{\circ} \mathrm{C}$ for $2 \mathrm{~h}$ (Figure 4a), and colony counting showed that less than $10 \%$ of $E$. coli survived (Figure $4 b$ ). TEM studies revealed that $\mathrm{rGO}$ nanosheets destroyed the membrane of $E$. coli in a way similar to that of GO nanosheets (Figure 4c). However, the cell viability of A549 was reduced to $\sim 47 \%$ and $\sim 15 \%$ with rGO nanosheets of 20 and $85 \mu \mathrm{g} / \mathrm{mL}$, respectively (Figure $4 \mathrm{~d}$ ). Therefore, rGO nanosheets possessed antibacterial properties that were only slightly lower than those of GO nanosheets, while their cytotoxicity was significantly higher than GO's. Such difference in cytotoxicity might arise from different surface charges and functional groups of GO and rGO nanosheet surfaces (Figure S1). ${ }^{42,45}$

Antibacterial Activity of $\mathbf{G O}$ and $\mathbf{r G O}$ Paper. Freestanding graphene-based paper is a highly useful material that combines flexibility and mechanical stiffness (Figure 1c,d). ${ }^{46,47}$ The antibacterial activity of GO and rGO paper was determined by using airborne bacteria tests. Aerosolized, airborne bacteria were imitated to sow the $E$. coli $\mathrm{DH} 5 \alpha$ cells on the paper, on which cold Luria-Bertani (LB) growth medium (with 1.5\% agar) was then spread. After overnight incubation at $37^{\circ} \mathrm{C}$, we could not find any cell growth on the GO paper (Figure $5 \mathrm{a}$ ) and only a limited number of E. coli colonies on the rGO paper (Figure $5 b)$, implying the superior antibacterial effect of such graphene-based papers. In contrast, control studies in the absence of either GO or rGO paper led to a great number of colony-forming units (CFU). SEM studies further confirmed that $E$. coli cells on the paper lost the integrity of membranes (Figure $5 c, d$ ), which was responsible for the bacteria-killing effect of the graphene-based paper. It is worth noting that a very recent study showed that bacteria did not grow on freestanding paper composed of a Tween/rGO composite, ${ }^{48}$ an effect arising from the surfactant Tween-based prevention of nonspecific binding (NSB) of bacteria rather than the graphene-based bacterial killing as reported in this work.

\section{CONCLUSIONS}

In summary, graphene-based nanomaterials have been found to be excellent antibacterial materials 
a

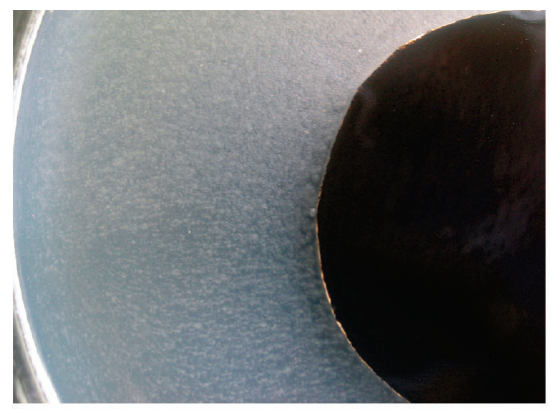

C

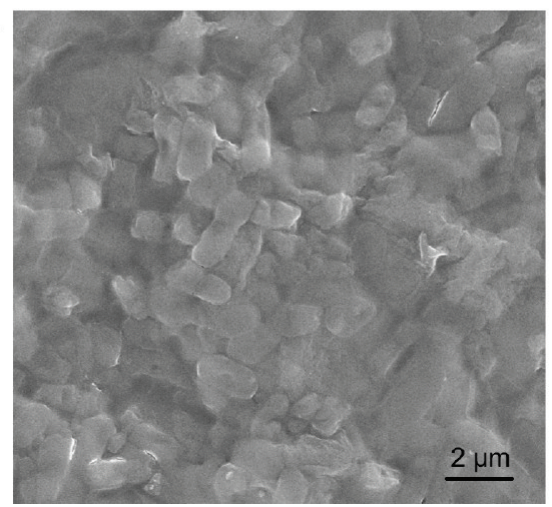

b

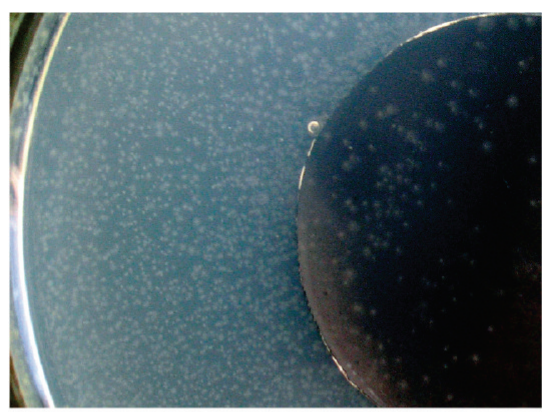

d

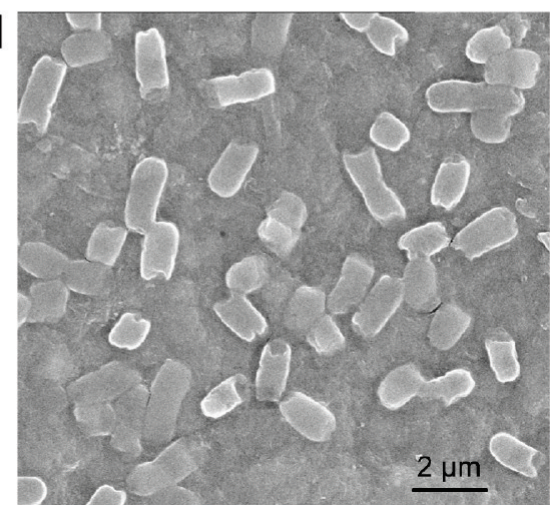

Figure 5. Antibacterial activity of GO and rGO paper. Photographs of $E$. coli growth on GO (a) and rGO (b) paper (overnight incubation at $37^{\circ} \mathrm{C}$ ). SEM images of $E$. coli attached to GO (c) and rGO (d) paper (12 h incubation at $37^{\circ} \mathrm{C}$ ).

with mild cytotoxicity. We have also demonstrated that macroscopic GO and rGO paper can be conveniently fabricated from their suspension via simple vacuum filtration. Given the superior antibacterial effect of GO nanosheets and the fact that GO nanosheets can be mass-produced and easily processed to make freestanding and flexible paper with low cost, we expect this new carbon nanomaterial could offer new opportunities for the development of antibacterial materials.

\section{MATERIALS AND METHODS}

Preparation and Characterization of the Graphene Nanomaterials. GO was prepared from purified natural graphite by the modified Hummers method, ${ }^{35}$ resulting in a colloidal suspension of GO sheets with a concentration of $0.85 \mathrm{mg} / \mathrm{mL}$. The $\mathrm{GO}$ was reduced to $\mathrm{rGO}$ by using hydrazine hydrate. ${ }^{49}$ In a typical procedure, GO $(0.85 \mathrm{mg} / \mathrm{mL}, 100 \mathrm{~mL})$ was loaded in a $250 \mathrm{~mL}$ round-bottom flask, to which hydrazine hydrate ( $1 \mathrm{~mL}, 50 \mathrm{wt} \%)$ was added and then heated in an oil bath at $80{ }^{\circ} \mathrm{C}$ under a water-cooled condenser for $24 \mathrm{~h}$. Residual hydrazine hydrate was removed via dialysis with distilled water.

Macroscopic GO paper and rGO paper were made by filtration of the suspension through a PVDF filter membrane $(47 \mathrm{~mm}$ in diameter, $220 \mathrm{~nm}$ pore size) via vacuum at room temperature. ${ }^{46}$ Paper could be easily peeled off from the filter paper. The thickness of the paper was controlled by adjusting the volume of the colloidal suspension.

The thickness of GO and rGO sheets was measured via atomic force microscopy (AFM), and the corresponding paper was measured via scanning electron microscopy (SEM).

Cell Culture and Cytotoxicity Test. A549 cells were grown in PRIM1640 (Invitrogen, USA) with 10\% heat-inactivated fetal bovine serum and antibiotics $(100 \mu \mathrm{g} / \mathrm{mL}$ of streptomycin and $100 \mathrm{U} / \mathrm{mL}$ of penicillin) at $37^{\circ} \mathrm{C}$ in $5 \% \mathrm{CO}_{2}$. Cells were seeded in 6- or 24-well plates and grown overnight prior to studies. Cells of $\sim 80 \%$ confluent were incubated with fresh media containing $\mathrm{GO}$ or $\mathrm{rGO}$ suspensions with different concentrations $(0,20$, and $85 \mu \mathrm{g} / \mathrm{mL})$. After $24 \mathrm{~h}, 50 \mu \mathrm{L}$ of a $5 \mathrm{mg} / \mathrm{mL}$ thiazolyl blue tetrazolium bromide (MTT, Sigma-Aldrich, USA) solution was added to each well of the 24 -well plate, followed by incubation at $37^{\circ} \mathrm{C}$ for $4 \mathrm{~h}$.
Then cells were lysed with $20 \%$ acid sodium dodecyl sulfate (SDS, Sigma, USA) solution. After centrifugation, the absorbance of the supernatants was measured at $570 \mathrm{~nm}$ by using a microplate reader (Bio-Rad 680, USA). Alternatively, treated cells were collected and counted with a blood counting chamber after being stained by trypan blue. In flow cytometry assays, treated cells were washed three times with ice-cold phosphate buffer (PBS) and then stained with propidium iodide (PI) and FITC labeled Annexin $\mathrm{V}$ by using an Apoptosis Detection Kit (Bipec, USA). Each experiment was independently performed at least three times.

Bacterial Culture. E. coli DH5 $\alpha$ (Clontech) cells were cultivated at $37^{\circ} \mathrm{C}$ and maintained on LB plates (Luria-Bertani broth, Lennox modification, with $1.5 \%$ agar). E. coli $\mathrm{DH} 5 \alpha$ cells were grown overnight in LB medium at $37^{\circ} \mathrm{C}$ and then harvested at the exponential growth phase via centrifugation. E. coli cells were washed twice to remove residual macromolecules and other growth medium constituents and then resuspended in sterile saline solution $(0.9 \% \mathrm{NaCl})$. The $E$. coli cells were quantified via $\mathrm{OD}_{600}$ measurements.

Cell Viability Test of $E$. coli with $\mathbf{G O}$ and $\mathbf{r G O}$ Suspensions. E. coli $\mathrm{DH} 5 \alpha$ cells were inoculated in saline solution containing $85 \mu \mathrm{g} / \mathrm{mL}$ $\mathrm{GO}$ or $\mathrm{rGO}$, with a final cell concentration of $10^{7} / \mathrm{mL}$. The mixture was incubated with gentle shaking for $2 \mathrm{~h}$ at $37^{\circ} \mathrm{C}$. The mixture was diluted to 106 -fold with a gradient method and then applied uniformly on three LB culture medium plates per gradient solution (with a blank control). These sheets were incubated at $37^{\circ} \mathrm{C}$ for $12 \mathrm{~h}$. The colony-forming units (CFU) were counted, and the percentage of activated cells was determined from the ratio of the number of cells in the mixture divided by the number of cells at the beginning of experiments. 
As a control, suspensions of $\mathrm{GO}$ and $\mathrm{rGO}$ were centrifugated at $\sim 19000 \mathrm{~g}$ for $10 \mathrm{~min}$ to remove nanomaterials. E. coli DH5 $\alpha$ cells were inoculated in LB medium containing $10 \%(\mathrm{v} / \mathrm{v})$ supernatants and distilled water with a final cell concentration of $10^{7}$ per $\mathrm{mL}$. After shaking at $37^{\circ} \mathrm{C}$ for $12 \mathrm{~h}$, the absorbance at $600 \mathrm{~nm}$ was measured.

Metabolic Activity Assays for E. coli. The BacTiter-Glo Microbial Cell Viability Assay (Promega, USA) provides a homogeneous method to measure the number of viable bacterial cells in cultures based on the quantification of ATP, which reflects the metabolic activity of cells. The mixture containing $E$. coli $\mathrm{DH} 5 \alpha$ cells and 85 $\mu \mathrm{g} / \mathrm{mL}$ nanomaterials was shaken for $2 \mathrm{~h}$ at $37^{\circ} \mathrm{C}$. Then $100 \mu \mathrm{L}$ of the mixture was added to $100 \mu \mathrm{L}$ of the BacTiter-Glo reagent solution, and the mixture was shaken in the dark at $37^{\circ} \mathrm{C}$ for 5 min. In a typical assay, the number of photons from the mixture was recorded for $1 \mathrm{~min}$, and the percentage of active cells was determined by the average number of photons.

Transmission Electron Microscopic Measurements. A549 cells treated with $\mathrm{GO}$ sheets and $E$. coli $\mathrm{DH} 5 \alpha$ cells with suspended $\mathrm{GO}$ or rGO for 30 min were fixed with $2.5 \%$ glutaraldehyde. The cells were washed with PBS and then postfixed with $1 \%$ aqueous $\mathrm{OsO}_{4}$ (Fluka) for $1 \mathrm{~h}$ and washed again twice with PBS. The cells then were dehydrated through ethanol series $(70 \%$ for $15 \mathrm{~min}$, $90 \%$ for $15 \mathrm{~min}$, and $100 \%$ for $15 \mathrm{~min}$ twice) and embedded in Epon/Araldite resin (polymerization at $65^{\circ} \mathrm{C}$ for $15 \mathrm{~h}$ ). Thin sections $(90 \mathrm{~nm})$ containing the cells were placed on the grids and stained for 1 min each with 4\% uranyl acetate (1:1 acetone/water) and $0.2 \%$ Raynolds lead citrate (water), air-dried, and examined under the transmission electron microscope (Joel JEM1230).

Scanning Electron Microscopic Measurements. A quantity of $100 \mu \mathrm{L}$ of $10^{6} / \mathrm{mL}$ cells suspended in solution was plated on an LB agar growth plate. After $1 \mathrm{~h}$ at $37^{\circ} \mathrm{C}$, the square papers were gently placed on the top of the inoculated agar plates to interact cells with materials. Then the plates were incubated at $37^{\circ} \mathrm{C}$ for $12 \mathrm{~h}$. The cells on papers were fixed with $2.5 \%$ glutaraldehyde and $1 \%$ osmium tetraoxide. The cells were sputter-coated with gold $(20 \mathrm{~s}, 30 \mathrm{~mA})$ and then imaged under an SEM (Hitachi S-2400) to study the morphology of cells on GO and rGO paper.

Airborne Bacteria Test. Collected E. coli DH5 $\alpha$ cells were diluted to $8.0 \times 10^{7} / \mathrm{mL}$. To imitate the aerosolized, airborne bacteria, the cell suspension in sterile saline solution was sprayed onto the paper that was placed in an empty sterile glass dish, at a rate of $\sim 20 \mathrm{~mL} / \mathrm{min}$ in a fume hood, which was then air-dried for 5 min. ${ }^{28}$ Autoclaved LB growth medium (with $1.5 \%$ agar) that was precooled to $40^{\circ} \mathrm{C}$ was added to the bacteria-exposed paper and dish. Once the agar solidified, the dish was incubated at $37^{\circ} \mathrm{C}$ overnight.

Acknowledgment. This work was supported by the NSFC (Nos. 20725516, 90913014), the MOST (No. 2007CB936000), the Ministry of Health (No. 2009ZX10004-301), and the Shanghai Municipal Commission for Science and Technology (Nos. 0852 nm00400, 0952 nm04600).

Supporting Information Available: A table and figures giving additional details of the study. This material is available free of charge via the Internet at http://pubs.acs.org.

\section{REFERENCES AND NOTES}

1. Geim, A. K.; Novoselov, K. S. The Rise of Graphene. Nat Mater. 2007, 6, 183-191.

2. Lee, C.; Wei, X.; Kysar, J. W.; Hone, J. Measurement of the Elastic Properties and Intrinsic Strength of Monolayer Graphene. Science 2008, 321, 385-388.

3. Stankovich, S.; Dikin, D. A.; Dommett, G. H. B.; Kohlhaas, K. M.; Zimney, E. J.; Stach, E. A.; Piner, R. D.; Nguyen, S. T.; Ruoff, R. S. Graphene-Based Composite Materials. Nature 2006, 442, 282-286.

4. Balandin, A. A.; Ghosh, S.; Bao, W.; Calizo, I.; Teweldebrhan, D.; Miao, F.; Lau, C. N. Superior Thermal Conductivity of Single-Layer Graphene. Nano Lett. 2008, 8, 902-907.

5. Novoselov, K. S.; Geim, A. K.; Morozov, S. V.; Jiang, D.; Zhang, Y.; Dubonos, S. V.; Grigorieva, I. V.; Firsov, A. A.
Electric Field Effect in Atomically Thin Carbon Films. Science 2004, 306, 666-669.

6. Novoselov, K. S.; Geim, A. K.; Morozov, S. V.; Jiang, D.; Katsnelson, M. I.; Grigorieva, I. V.; Dubonos, S. V.; Firsov, A. A. Two-Dimensional Gas of Massless Dirac Fermions in Graphene. Nature 2005, 438, 197-200.

7. Zhang, Y.; Tan, Y.-W.; Stormer, H. L.; Kim, P. Experimental Observation of the Quantum Hall Effect and Berry's Phase in Graphene. Nature 2005, 438, 201-204.

8. Geim, A. K. Graphene: Status and Prospects. Science 2009, 324, 1530-1534.

9. Zhang, Y.; Small, J. P.; Amori, M. E. S.; Kim, P. Electric Field Modulation of Galvanomagnetic Properties of Mesoscopic Graphite. Phys. Rev. Lett. 2005, 94, 176803.

10. Li, D.; Muller, M. B.; Gilje, S.; Kaner, R. B.; Wallace, G. G. Processable Aqueous Dispersions of Graphene Nanosheets. Nat. Nanotechnol. 2008, 3, 101-105.

11. Luk'anchuk, I. A.; Kopelevich, Y. Dirac and Normal Fermions in Graphite and Graphene: Implications of the Quantum Hall Effect. Phys. Rev. Lett. 2006, 97, 256801.

12. Lin, Y. M.; Dimitrakopoulos, C.; Jenkins, K. A.; Farmer, D. B.; Chiu, H. Y.; Grill, A.; Avouris, P. 100-GHz Transistors from Wafer-Scale Epitaxial Graphene. Science 2010, 327, 662.

13. Dong, X.; Shi, Y.; Huang, W.; Chen, P.; Li, L.-J. Electrical Detection of DNA Hybridization with Single-Base Specificity Using Transistors Based on CVD-Grown Graphene Sheets. Adv. Mater. 2010, 22, 1649-1653.

14. He, Q.; Sudibya, H. G.; Yin, Z.; Wu, S.; Li, H.; Boey, F.; Huang, W.; Chen, P.; Zhang, H. Centimeter-Long and Large-Scale Micropatterns of Reduced Graphene Oxide Films: Fabrication and Sensing Applications. ACS Nano 2010, 4, 3201-3208.

15. Wang, X.; Zhi, L.; Tsao, N.; Tomović, Z.; Li, J.; Müllen, K. Transparent Carbon Films as Electrodes in Organic Solar Cells. Angew. Chem., Int. Ed. 2008, 47, 2990-2992.

16. Wang, X.; Zhi, L.; Müllen, K. Transparent, Conductive Graphene Electrodes for Dye-Sensitized Solar Cells. Nano Lett. 2008, 8, 323-327.

17. Yin, Z.; Wu, S.; Zhou, X.; Huang, X.; Zhang, Q.; Boey, F.; Zhang, H. Electrochemical Deposition of ZnO Nanorods on Transparent Reduced Graphene Oxide Electrodes for Hybrid Solar Cells. Small 2010, 6, 307-312.

18. Schedin, F.; Geim, A. K.; Morozov, S. V.; Hill, E. W.; Blake, P.; Katsnelson, M. I.; Novoselov, K. S. Detection of Individual Gas Molecules Adsorbed on Graphene. Nat. Mater. 2007, 6, 652-655.

19. Wang, Z.; Zhou, X.; Zhang, J.; Boey, F.; Zhang, H. Direct Electrochemical Reduction of Single-Layer Graphene Oxide and Subsequent Functionalization with Glucose Oxidase. J. Phys. Chem. C 2009, 113, 14071-14075.

20. Chen, H.; Müler, M. B.; Gilmore, K., J.; Wallace, G., G.; Li, D. Mechanically Strong, Electrically Conductive, and Biocompatible Graphene Paper. Adv. Mater. 2008, 20, 3557-3561.

21. Sun, X.; Liu, Z.; Welsher, K.; Robinson, J.; Goodwin, A.; Zaric, S.; Dai, H. Nano-Graphene Oxide for Cellular Imaging and Drug Delivery. Nano Res. 2008, 1, 203-212.

22. Liu, Z.; Robinson, J. T.; Sun, X.; Dai, H. PEGylated Nanographene Oxide for Delivery of Water-Insoluble Cancer Drugs. J. Am. Chem. Soc. 2008, 130, 10876-10877.

23. Moran, A.; Israela, B.; Meital, Z. Gentamicin-Loaded Bioresorbable Films for Prevention of Bacterial Infections Associated with Orthopedic Implants. J. Biomed. Mater. Res., Part A 2007, 83A, 10-19.

24. Ramstedt, M.; Cheng, N.; Azzaroni, O.; Mossialos, D.; Mathieu, H. J.; Huck, W. T. S. Synthesis and Characterization of Poly(3-Sulfopropylmethacrylate) Brushes for Potential Antibacterial Applications. Langmuir 2007, 23, 3314-3321.

25. Allison, B. C.; Applegate, B. M.; Youngblood, J. P. Hemocompatibility of Hydrophilic Antimicrobial Copolymers of Alkylated 4-Vinylpyridine. Biomacromolecules 2007, 8, 2995-2999.

26. Stewart, P. S.; Costerton, J. W. Antibiotic Resistance of Bacteria in Biofilms. Lancet 2001, 358, 135-138. 
27. Adolfsson-Erici, M.; Pettersson, M.; Parkkonen, J.; Sturve, J. Triclosan, a Commonly Used Bactericide Found in Human Milk and in the Aquatic Environment in Sweden. Chemosphere 2002, 46, 1485-1489.

28. Kumar, A.; Vemula, P. K.; Ajayan, P. M.; John, G. SilverNanoparticle-Embedded Antimicrobial Paints Based on Vegetable Oil. Nat. Mater. 2008, 7, 236-241.

29. Wei, C.; Lin, W. Y.; Zainal, Z.; Williams, N. E.; Zhu, K.; Kruzic, A. P.; Smith, R. L.; Rajeshwar, K. Bactericidal Activity of $\mathrm{TiO}_{2}$ Photocatalyst in Aqueous Media: Toward a SolarAssisted Water Disinfection System. Environ. Sci. Technol. 2002, 28, 934-938.

30. Magrez, A.; Kasas, S.; Salicio, V.; Pasquier, N.; Seo, J. W.; Celio, M.; Catsicas, S.; Schwaller, B.; Forro, L. Cellular Toxicity of Carbon-Based Nanomaterials. Nano Lett. 2006, $6,1121-1125$.

31. Warheit, D. B.; Laurence, B. R.; Reed, K. L.; Roach, D. H.; Reynolds, G. A. M.; Webb, T. R. Comparative Pulmonary Toxicity Assessment of Single-Wall Carbon Nanotubes in Rats. Toxicol. Sci. 2004, 77, 117-125.

32. Schipper, M. L.; Nakayama-Ratchford, N.; Davis, C. R.; Kam, N. W. S.; Chu, P.; Liu, Z.; Sun, X.; Dai, H.; Gambhir, S. S. A Pilot Toxicology Study of Single-Walled Carbon Nanotubes in a Small Sample of Mice. Nat. Nanotechnol. 2008, 3 216-221.

33. Chen, X.; Tam, U. C.; Czlapinski, J. L.; Lee, G. S.; Rabuka, D.; Zettl, A.; Bertozzi, C. R. Interfacing Carbon Nanotubes with Living Cells. J. Am. Chem. Soc. 2006, 128, 6292-6293.

34. Agarwal, S.; Zhou, X.; Ye, F.; He, Q.; Chen, G. C. K.; Soo, J.; Boey, F.; Zhang, H.; Chen, P. Interfacing Live Cells with Nanocarbon Substrates. Langmuir 2010, 26, 2244-2247.

35. Hummers, W. S.; Offeman, R. E. Preparation of Graphitic Oxide. J. Am. Chem. Soc. 1958, 80, 1339.

36. Xu, Y.; Bai, H.; Lu, G.; Li, C.; Shi, G. Flexible Graphene Films via the Filtration of Water-Soluble Noncovalent Functionalized Graphene Sheets. J. Am. Chem. Soc. 2008, 130, 5856-5857.

37. Luo, C.; Zuo, X.; Wang, L.; Wang, E.; Song, S.; Wang, J.; Wang, J.; Fan, C.; Cao, Y. Flexible Carbon NanotubePolymer Composite Films with High Conductivity and Superhydrophobicity Made by Solution Process. Nano Lett. 2008, 8, 4454-4458.

38. Kang, S.; Pinault, M.; Pfefferle, L. D.; Elimelech, M. SingleWalled Carbon Nanotubes Exhibit Strong Antimicrobial Activity. Langmuir 2007, 23, 8670-8673.

39. Kang, S.; Herzberg, M.; Rodrigues, D. F.; Elimelech, M. Antibacterial Effects of Carbon Nanotubes: Size Does Matter! Langmuir 2008, 24, 6409-6413.

40. Manna, S. K.; Sarkar, S.; Barr, J.; Wise, K.; Barrera, E. V.; Jejelowo, O.; Rice-Ficht, A. C.; Ramesh, G. T. Single-Walled Carbon Nanotube Induces Oxidative Stress and Activates Nuclear Transcription Factor-кB in Human Keratinocytes. Nano Lett. 2005, 5, 1676-1684.

41. Nel, A.; Xia, T.; Madler, L.; Li, N. Toxic Potential of Materials at the Nanolevel. Science 2006, 311, 622-627.

42. Tang, Y. J.; Ashcroft, J. M.; Chen, D.; Min, G.; Kim, C.-H.; Murkhejee, B.; Larabell, C.; Keasling, J. D.; Chen, F. F. Charge-Associated Effects of Fullerene Derivatives on Microbial Structural Integrity and Central Metabolism. Nano Lett. 2007, 7, 754-760.

43. Ding, L.; Stilwell, J.; Zhang, T.; Elboudwarej, O.; Jiang, H.; Selegue, J. P.; Cooke, P. A.; Gray, J. W.; Chen, F. F. Molecular Characterization of the Cytotoxic Mechanism of Multiwall Carbon Nanotubes and Nano-Onions on Human Skin Fibroblast. Nano Lett. 2005, 5, 2448-2464.

44. Narayan, R. J.; Berry, C. J.; Brigmon, R. L. Structural and Biological Properties of Carbon Nanotube Composite Films. Mater. Sci. Eng., B 2005, 123, 123-129.

45. Szabo, T.; Berkesi, O.; Forgo, P.; Josepovits, K.; Sanakis, Y.; Petridis, D.; Dekany, I. Evolution of Surface Functional Groups in a Series of Progressively Oxidized Graphite Oxides. Chem. Mater. 2006, 18, 2740-2749.

46. Dikin, D. A.; Stankovich, S.; Zimney, E. J.; Piner, R. D.; Dommett, G. H. B.; Evmenenko, G.; Nguyen, S. T.; Ruoff,
R. S. Preparation and Characterization of Graphene Oxide Paper. Nature 2007, 448, 457-460.

47. Yuan, J.; Liu, X.; Akbulut, O.; Hu, J.; Suib, S. L.; Kong, J.; Stellacci, F. Superwetting Nanowire Membranes for Selective Absorption. Nat. Nanotechnol. 2008, 3, 332-336.

48. Park, S.; Mohanty, N.; Suk, J. W.; Nagaraja, A.; An, J.; Piner, R., D.; Cai, W.; Dreyer, D., R.; Berry, V.; Ruoff, R., S. Biocompatible, Robust Free-Standing Paper Composed of a TWEEN/Graphene Composite. Adv. Mater. 2010, 22, 1736-1740.

49. Stankovich, S.; Dikin, D. A.; Piner, R. D.; Kohlhaas, K. A.; Kleinhammes, A.; Jia, Y.; Wu, Y.; Nguyen, S. T.; Ruoff, R. S. Synthesis of Graphene-Based Nanosheets via Chemical Reduction of Exfoliated Graphite Oxide. Carbon 2007, 45, 1558-1565. 